\title{
Effect of Migraine Headache on Productivity of Patients According to Migraine Disability Assessment Score: A Cross-Sectional Study
}

\author{
Shafaq Jawed • Waqar Ali • Uzair Yaqoob (D) - Shahnaz Shah • \\ Syed Mohammad Mazhar Uddin · Aatera Haq
}

Received: April 21, 2019 / Published online: July 9, 2019

(C) The Author(s) 2019

\begin{abstract}
Introduction: Migraine, a primary headache disorder, is usually recurrent with moderate to severe intensity. Migraine is the third most common cause of disability under the age of 50 . There are various scoring systems for assessing this disability, one of which is MIDAS; the Migraine Disability Assessment Score. The objective of our study was to determine the extent of disability among migraine patients, patterns of prophylaxis, and their healthcareseeking behaviors.

Methods: This survey was done in 50 migraine patients at Jinnah postgraduate medical Centre from April to May 2018. The questionnaire inquired about the demographic information, management of migraine, and effect of this condition on their sleep, and the last part had
\end{abstract}

Enhanced digital features To view enhanced digital features for this article go to https://doi.org/10.6084/ m9.figshare.8320586.

S. Jawed

Jinnah Sindh Medical University, Karachi, Pakistan

W. Ali · U. Yaqoob (ه) · S. M. M. Uddin · A. Haq

Dow University of Health Sciences, Karachi,

Pakistan

e-mail: ozair_91393@hotmail.com

S. Shah

Jinnah Postgraduate Medical Centre, Karachi,

Pakistan assessment to know about their functional disability.

Results: The majority of the patients were females with a mean age of $31 \pm 10$ years. Acetaminophen was the most common medication used during a migraine attack, followed by nonsteroidal anti-inflammatory drugs. Only $54 \%$ of subjects admitted using prophylaxis, out of which $94 \%$ had stopped taking it after some time, with the most common reason being their side effects. $\beta$-blockers were the most common prophylaxis used. Only $32 \%$ had a regular follow-up visit with their doctors. Patients were graded according to the MIDAS score as: little or no disability, 22\%; mild disability, $14 \%$; moderate disability, 24\%; and severe disability, 40\%. Conclusions: The majority of migraine patients were found to have severe disability, which affected their daily work and social activities. Despite an increase in disability rate due to migraine, people do not seek regular medical care for this type of headache in Pakistan.

Keywords: Functional disability; Headache; Loss of productivity; Migraine

\section{INTRODUCTION}

Migraine is one of the primary headache disorders, associated with nausea, vomiting, and sensitivity to light, sound, or smell. An episode of this type of headache is usually recurrent 
with moderate to severe intensity. Global prevalence of migraine is $15 \%$, while that in eastern India alone was recorded as $14.2 \%$ [1-4]. Globally, migraine is the most common type of headache among individuals aged 20-40-yearold, with the highest occurrence being around the age of 40 , known to be the age of the maximum workforce $[5,6]$. According to a nationwide survey, the 1-year prevalence of migraine in Pakistan is $22.7 \%$, mostly affecting the age group between 40 and 49 years [7]. It is one of the most common diseases and is the third most common cause of disability under the age of 50 [4].

Migraine symptoms significantly affect the life style of the patient, with a reduction in social activities and professional capacity [8]. It results in high costs, particularly those associated with reduced productivity, work time (alone exceeding those of medical care), and ultimately, unemployment [5,6]. Migraine is a risk factor for sleep disturbances, depression, anxiety, and stress. These factors further promote disability in migraine patients. Longstanding migraine also leads to cognitive dysfunction that causes absenteeism or decreased work performance and can impact the socio-economic status of the patient [9].

It is evident that migraine limits the skills of an individual such as problem solving, speaking, and driving [6]. A significant association between migraine and excessive daytime sleepiness (EDS) was found, with the latter increasing with increased frequency of the headache [10]. Prophylactic treatment considerably reduces anxiety, depression, and disability symptoms [11].

The onset of headache was earlier in patients with migraine, who reported a first-degree family history of the disease [12]. Research conducted on medical students of Karachi, Pakistan, revealed that migraine was the most common type of headache among the target population. A high self-medication rate was observed as a result of disturbed sleep pattern and stress, with avoidance of academics, extracurricular activities, family and friends [13]. According to another study conducted in Khyber Pakhtunkhwa Province of Pakistan, migraine frequency was higher in females than males, and it was more in the age group of above 30 years. Most of the migraine patients (40.2\%) did not visit the hospital and preferred self-medication [14].

The degree of disability is often used as a parameter to determine disease severity and prescribe medication. For this purpose, different scoring systems have been suggested, one of which is MIDAS; the Migraine Disability Assessment Score. MIDAS is a standardized questionnaire that determines the severity of disability by assessment of the level of pain among the affected individuals [15]. Many studies have proved that the MIDAS score often correlates with a physician's assessment of migraine and is a useful tool for establishing the level of care and treatment required $[3,4,16,17]$. The aim of our study was to evaluate migraine-associated disability among the population in Pakistan using the MIDAS questionnaire.

There are limited data available regarding migraine-associated costs and disability in Pakistan and the findings of our work will contribute towards the existing studies. The purpose of our research is to determine the extent of disability among migraine patients in the region, patterns of prophylaxis, and healthcare-seeking behaviors among the effected group.

\section{METHODS}

This cross-sectional survey was carried out at the outpatient department of the neurological ward of Jinnah Postgraduate Medical Centre (JPMC), Karachi, Pakistan. In a time period of 2 months (April and May 2018), the questionnaire was filled out by 50 individuals with migraine. Migraine was already diagnosed by a senior neurologist based on International Classification of Headache Disorders, 3rd edition [18]. Participants were included after consenting to the study, which was approved by the ethical committee of JPMC. Those denying the consent and those less than 14 years of age were excluded. The study was performed in accordance with the Helsinki Declaration of 1964 and its later amendments. The questionnaire 
was modified after performing a pilot study and going through previous similar studies.

The questionnaire was comprised of three parts, the first part inquired about demographic information, while the second part consisted of questions regarding the use of medications during the migraine attack, prophylaxis taken, and pattern of visiting health care facility during or after the migraine symptoms. Moreover, the subjects were asked about their sleeping habits and the possible effect of migraine on their sleeping patterns was assessed based on the participant's self-interpretation. The third part of questionnaire had assessment for calculating the MIDAS score, that is, an inability/reduced ability of more than $50 \%$ to attend work or school, the inability/reduced ability to do household work, the inability to participate in non-work-related activities (total scores: 0-3 in each headache attack) [15].

The score was interpreted as follows: Grade 1, little or no disability (0-5); Grade 2, mild disability (6-10); Grade 3, moderate disability (11-20); and Grade 4, severe disability (>21). Data entry and analysis were done by using SPSS version 23.

\section{RESULTS}

A total of 50 migraine subjects contributed to this study out of 55 screened individuals. The remaining five were not willing to participate. Mean age of the individuals was $31 \pm 10$ years, among which $82 \%$ were females and $18 \%$ were males. Approximately $68 \%$ of females were housewives. Married individuals with migraine were greater as compared to unmarried (64 vs. $36 \%$ ) (Table 1).

The pattern of medication and prophylaxis used by migraine subjects is summarized in Table 2. Acetaminophen was the most common medication used by the individuals during a migraine attack (48\%), followed by nonsteroidal anti-inflammatory drugs (40\%). Many individuals did not take any prophylaxis (46\%) and the majority (54\%) of subjects admitted using prophylaxis. Among this group, $94 \%$ of people had stopped taking prophylaxis before the end of treatment, with the most common reason for
Table 1 Socio-demographic factors

\begin{tabular}{lcl}
\hline & Frequency $(\boldsymbol{n})$ & Proportion (\%) \\
\hline Gender & 9 & 18 \\
Male & 41 & 82 \\
Female & & \\
Occupation & 34 & 68.0 \\
Housewife & 12 & 24.0 \\
Student & 4 & 8.0 \\
Others & & \\
Marital status & 18 & 36.0 \\
Single & 32 & 64.0 \\
Married & & \\
\hline
\end{tabular}

this being their side effects. $\beta$-blockers were the most common prophylaxis used (20\%), followed by tricyclic antidepressants (18\%). The majority of patients felt that they have developed tolerance. There was a lower tendency of going to follow-ups with health care among individuals with migraine and only $32 \%$ had a follow-up visit with doctors.

Average hours of sleep among the data was $6.56 \mathrm{~h}$. Table 3 shows the summary of MIDAS score questionnaire. The average score was 22.42 , while the grading was as follows: Grade 1 $(0-5), 22 \% \quad(n=11) ; \quad$ Grade $2(6-10), 14 \%$ $(n=7)$; Grade $3(11-20), 24 \%(n=12) ;$ and Grade $4(>21)$, $40 \%(n=20)$.

\section{DISCUSSION}

The disability prevalence associated with migraine is large and concerning, with chronic migraine patients being affected more [19]. Individuals suffering from migraine-related disability experience difficulties in maintaining a work and household routine and struggle with socializing activities, which is consistent with the results of our study [20]. Moreover, studies have shown that gender has a direct effect on the intensity of migraine attacks. A study reported a higher prevalence of severe migraine 
Table 2 Symptomatic treatment and prophylaxis

\begin{tabular}{|c|c|c|}
\hline & $\begin{array}{l}\text { Frequency } \\
(n)\end{array}$ & $\begin{array}{l}\text { Proportion } \\
(\%)\end{array}$ \\
\hline \multicolumn{3}{|l|}{$\begin{array}{l}\text { Drug for symptomatic } \\
\text { treatment }\end{array}$} \\
\hline None & 3 & 6 \\
\hline Acetaminophen & 24 & 48 \\
\hline NSAID & 20 & 40 \\
\hline Combination & 3 & 6 \\
\hline \multicolumn{3}{|l|}{ Prophylaxis status } \\
\hline $\begin{array}{l}\text { Never taken because doctor } \\
\text { did not prescribe }\end{array}$ & 15 & 30 \\
\hline Currently on prophylaxis & 6 & 12 \\
\hline $\begin{array}{l}\text { Completed as advised by } \\
\text { physician }\end{array}$ & 17 & 34 \\
\hline Did not go to doctor & 4 & 8 \\
\hline $\begin{array}{l}\text { Quit after taking for some } \\
\text { time }\end{array}$ & 5 & 10 \\
\hline $\begin{array}{l}\text { Never taken even after } \\
\text { prescription }\end{array}$ & 2 & 4 \\
\hline Taken but non-compliant & 1 & 2 \\
\hline \multicolumn{3}{|l|}{ Drug for prophylaxis } \\
\hline None & 23 & 46 \\
\hline Beta-blocker & 10 & 20 \\
\hline Valproate & 5 & 10 \\
\hline Tricyclic antidepressant & 9 & 18 \\
\hline Topiramate & 3 & 6 \\
\hline
\end{tabular}

in females as compared to males and females suffered greater migraine-related disabilities [21]. A study conducted in Psychiatry Tertiary Care Hospital in New Delhi revealed that $66.0 \%$ of females with migraines scored low on the Female Sexual Function Index, an indication of lower sexuality as compared to the control group (33\%) [22]. Our study showed $\beta$-blockers as the most common prophylactic used for migraine, however this is different from the
Table 3 MIDAS score

\begin{tabular}{lll}
\hline & $\begin{array}{l}\text { Frequency } \\
(\boldsymbol{n})\end{array}$ & $\begin{array}{l}\text { Proportion } \\
(\%)\end{array}$ \\
\hline $\begin{array}{l}\text { MIDAS score } \\
(23 \pm 2)\end{array}$ & & \\
Grade 1 & 11 & 22 \\
Grade 2 & 7 & 14 \\
Grade 3 & 12 & 24 \\
Grade 4 & 20 & 40 \\
\hline
\end{tabular}

finding in another study where the use of antidepressants was more common [23]. The same study also revealed that the use of prophylaxis increased with an increasing age, however, no such relation was observed in our study. Although beneficial to some extent, these medications have been known to cause dizziness, chest pressure, and muscle weakness, due to overuse, especially in chronic migraine [24, 25]. A study on 1200 individuals revealed that a large number of patients stopped taking prophylaxis prescribed by the doctor primarily due to decreased efficacy or side effects $[23,26]$.

The study is limited by its size, the absence of consideration of comorbidities, and lack of randomization. Secondly, since this is a crosssectional study, there was no control group, and the presence of one would have given us more meaningful results. The onset of diagnosis, frequency, and duration of attacks were also not taken into regard. Lastly, due to irregularities regarding duration and frequency of medication, we could not include the exact values in the data.

\section{CONCLUSIONS}

Our study concludes that the majority of migraine patients have grade 4 , that is, severe disability. In addition to reduced sleep hours, this factor effects their daily work-related as well as social activities. Most of the results in our study are consistent with migraine-related studies conducted in other countries. Despite 
an increase in disability rate due to migraine, the trend of people towards seeking regular medical care and prophylaxis is low in Pakistan.

\section{ACKNOWLEDGEMENTS}

We thank the participants of the study.

Funding. No funding or sponsorship was received for this study or publication of this article.

Authorship. All named authors meet the International Committee of Medical Journal Editors (ICMJE) criteria for authorship for this article, take responsibility for the integrity of the work as a whole, and have given their approval for this version to be published.

Disclosures. Shafaq Jawed, Waqar Ali, Uzair Yaqoob, Shahnaz Shah, Syed Mohammad Mazhar Uddin, and Aatera Haq have nothing to disclose.

Compliance with Ethics Guidelines. The study was approved by the Institutional Review Board of Jinnah Postgraduate Medical Centre. Informed consent was taken from each participant before providing the questionnaire. The study was performed in accordance with the Helsinki Declaration of 1964 and its later amendments.

Data Availability. The datasets used and/or analyzed during the current study are available from the corresponding author on reasonable request.

Open Access. This article is distributed under the terms of the Creative Commons Attribution-NonCommercial 4.0 International License (http://creativecommons.org/licenses/ by-nc/4.0/), which permits any noncommercial use, distribution, and reproduction in any medium, provided you give appropriate credit to the original author(s) and the source, provide a link to the Creative Commons license, and indicate if changes were made.

\section{REFERENCES}

1. Aminoff RP, Simon DA, Greenberg MJ, editors. Clinical neurology. 7th ed. New York: Lange Medical Books/McGraw-Hill; 2009. p. 85-8.

2. World Health Organisation-Headache disorders Fact sheet No. 277. 2016.

3. Zandifar A, Asgari F, Haghdoost F, Masjedi SS, Manouchehri N, Banihashemi M, et al. Reliability and validity of the migraine disability assessment scale among migraine and tension type headache in Iranian patients. Biomed Res Int. 2014;2014:2014:978064. https://doi.org/10.1155/ $2014 / 978064$.

4. Lipton RB, Stewart WF, Sawyer J, Edmeads JG. Clinical utility of an instrument assessing migraine disability: the migraine disability assessment (MIDAS) questionnaire. Headache J Head Face Pain. 2001;41(9):854-61.

5. Raggi A, Covelli V, Leonardi M, Grazzi L, Curone M, D'Amico D. Difficulties in work-related activities among migraineurs are scarcely collected: results from a literature review. Neurol Sci. 2014;35(1):23-6.

6. Baigi K, Stewart WF. Headache and migraine. a leading cause of absenteeism. Handb Clin Neurol. 2015;131:447-63. https://doi.org/10.1016/ B978-0-444-62627-1.00025-1.

7. Herekar AA, Ahmad A, Uqaili UL, Ahmed B, Effendi J, Alvi SZ, et al. Primary headache disorders in the adult general population of Pakistan-a cross-sectional nationwide prevalence survey. J Headache Pain. 2017;18(1):28. https://doi.org/10.1186/ s10194-017-0734-1.

8. Leonardi M, Steiner TJ, Scher AT, Lipton RB. The global burden of migraine: measuring disability in headache disorders with WHO's Classification of Functioning, Disability and Health (ICF). J Headache Pain. 2005;6(6):429.

9. Yalinay Dikmen P, Yavuz BG, Aydinlar EI. The relationships between migraine, depression, anxiety, stress, and sleep disturbances. Acta Neurol Belg. 2015;115(2):117-22.

10. Stavem K, Kristiansen HA, Kristoffersen ES, Kværner KJ, Russell MB. Association of excessive daytime sleepiness with migraine and headache frequency in the general population. J Headache Pain. 2017;18(1):35.

11. Bendtsen L, Munksgaard SB, Tassorelli C, Nappi G, Katsarava Z, Lainez M, et al. Disability, anxiety and depression associated with medication-overuse 
headache can be considerably reduced by detoxification and prophylactic treatment. Results from a multicentre, multinational study (COMOESTAS project). Cephalalgia. 2014;34(6):426-33.

12. Murtaza M, Kisat $M$, Daniel $H$, Sonawalla AB. Classification and clinical features of headache disorders in Pakistan: a retrospective review of clinical data. PLoS One. 2009;4(6):e5827.

13. Noor T, Sajjad A, Asma A. Frequency, character and predisposing factor of headache among students of medical college of Karachi. J Pak Med Assoc. 2016;66(2):159-64.

14. Zahid M, Sthanadar AA, Kaleem M, Latif M, Sthanadar IA, Ali PA, Ismail $M$, Imtiaz N, Shah $M$. Prevalence and perceptions about migraine among students and patients in Khyber Pakhtunkhwa Province, Pakistan. Adv Biosci Biotechnol. 2014;5(6):508-16.

15. Stewart WF, Lipton RB, Dowson AJ, Sawyer J. Development and testing of the Migraine Disability Assessment (MIDAS) Questionnaire to assess headache-related disability. Neurology. 2001;56(6 Suppl 1):S20-8.

16. García ML, Baos V, Láinez M, Pascual J, López-Gil A. Responsiveness of migraine-ACT and MIDAS questionnaires for assessing migraine therapy. Headache J Head Face Pain. 2008;48(9):1349-55.

17. Ghorbani A, Chitsaz A. Comparison of validity and reliability of the Migraine Disability Assessment (MIDAS) versus headache impact test (HIT) in an Iranian population. Iran J Neurol. 2011;10(3-4):39-42.

18. Headache Classification Committee of the International Headache Society (IHS) The International Classification of Headache Disorders, 3rd edn. Cephalalgia. 2018;38(1):1-211.

19. Buse DC, Manack AN, Fanning KM, Serrano D, Reed ML, Turkel CC, et al. Chronic migraine prevalence, disability, and sociodemographic factors: results from the American Migraine Prevalence and Prevention Study. Headache. 2012;52(10):1456-70.

20. D’Amico D, Grazzi L, Curone M, Di Fiore P, Proietti Cecchini A, Leonardi M, et al. Difficulties in work activities and the pervasive effect over disability in patients with episodic and chronic migraine. Neurol Sci Off J Ital Neurol Soc Ital Soc Clin Neurophysiol. 2015;36(Suppl 1):9-11.

21. Park JW, Shin HE, Kim JS, Lee KS. Assessing migraine disability by diary-based measurement: relationship to the characteristics of individual headache attacks. Eur J Neurol. 2008;15(8):817-21.

22. Nagpal M, Jangid R, Sathyanarayan Rao T. A comparative study of the sexual functioning of women with primary headache in India. Indian J Psychiatry. 2018;60(2):224-8. https://doi.org/10.4103/ psychiatry.IndianJPsychiatry_290_17.

23. Blumenfeld AM, Bloudek LM, Becker WJ, Buse DC, Varon SF, Maglinte GA, et al. Patterns of use and reasons for discontinuation of prophylactic medications for episodic migraine and chronic migraine: results from the second international burden of migraine study (IBMS-II). Headache. 2013;53(4):644-55.

24. Martelletti P. Floating out migraine disability thickened by medication overuse. Eur J Neurol. 2018;25(10):1193-4. https://doi.org/10.1111/ ene. 13736 .

25. Usai S, Grazzi L, Andrasik F, D'Amico D, Rigamonti A, Bussone G. Chronic migraine with medication overuse: treatment outcome and disability at 3 years follow-up. Neurol Sci Off J Ital Neurol Soc Ital Soc Clin Neurophysiol. 2004;25(Suppl 3):S272-3.

26. Holland S, Fanning KM, Serrano D, Buse DC, Reed $\mathrm{ML}$, Lipton RB. Rates and reasons for discontinuation of triptans and opioids in episodic migraine: results from the American Migraine Prevalence and Prevention (AMPP) study. J Neurol Sci. 2013;326(1-2):10-7. 